\title{
Redox reactions of iron and manganese oxides in complex systems
}

\author{
Jianzhi Huang, Huichun Zhang (ه) \\ Department of Civil and Environmental Engineering, Case Western Reserve University, Cleveland, OH 44106, USA
}

\section{H I G H L I G H T S}

- Mechanisms of redox reactions of Fe- and Mnoxides were discussed.

- Oxidative reactions of $\mathrm{Mn}$ - and Fe-oxides in complex systems were reviewed.

- Reductive reaction of $\mathrm{Fe}(\mathrm{II}) /$ iron oxides in complex systems was examined.

- Future research on examining the redox reactivity in complex systems was suggested.

\section{A R T I C LE IN F O}

Article history:

Received 30 December 2019

Revised 28 February 2020

Accepted 21 March 2020

Available online 16 May 2020

\section{Keywords:}

Iron oxides

Manganese oxides

Reduction

Oxidation

Complex systems

Reaction kinetics and mechanisms

\section{GRAPHIC A B T RACT}

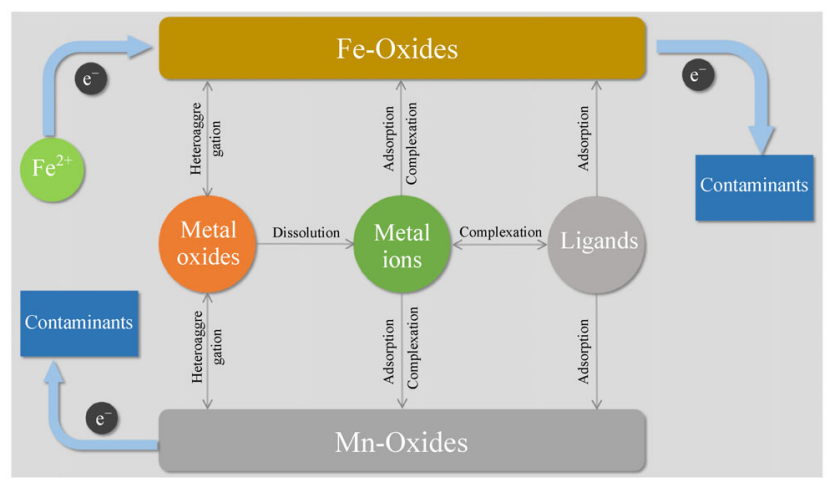

\begin{abstract}
A B S T R A C T
Conspectus: Redox reactions of $\mathrm{Fe}$ - and Mn-oxides play important roles in the fate and transformation of many contaminants in natural environments. Due to experimental and analytical challenges associated with complex environments, there has been a limited understanding of the reaction kinetics and mechanisms in actual environmental systems, and most of the studies so far have only focused on simple model systems. To bridge the gap between simple model systems and complex environmental systems, it is necessary to increase the complexity of model systems and examine both the involved interaction mechanisms and how the interactions affected contaminant transformation. In this Account, we primarily focused on (1) the oxidative reactivity of $\mathrm{Mn}$ - and Fe-oxides and (2) the reductive reactivity of $\mathrm{Fe}(\mathrm{II}) /$ iron oxides in complex model systems toward contaminant degradation. The effects of common metal ions such as $\mathrm{Mn}^{2+}, \mathrm{Ca}^{2+}, \mathrm{Ni}^{2+}, \mathrm{Cr}^{3+}$ and $\mathrm{Cu}^{2+}$, ligands such as small anionic ligands and natural organic matter (NOM), and second metal oxides such as $\mathrm{Al}, \mathrm{Si}$ and $\mathrm{Ti}$ oxides on the redox reactivity of the systems are briefly summarized.
\end{abstract}

(C) The Author(s) 2020. This article is published with open access at link.springer.com and journal.hep. com.cn 2020

\section{Introduction}

Iron and manganese are the first and third most abundant transition metals in the earth's crust (Martin, 2005). Redox reactions of $\mathrm{Fe}$ - and $\mathrm{Mn}$-oxides play essential roles in the fate and transformation of numerous organic and inorganic contaminants in the environment (Klausen et al., 1995;

$\triangle$ Corresponding author

E-mail: hjz13@case.edu

Special Issue-Accounts of Aquatic Chemistry and Technology Research (Responsible Editors: Jinyong Liu, Haoran Wei \& Yin Wang)
Zhang et al., 2008; Zhang and Weber, 2013) and the global geochemical cycles of many elements, such as $\mathrm{O}, \mathrm{N}, \mathrm{P}$ and $\mathrm{S}$ (Borch et al., 2010; Sunda, 2010). These reactions have been widely accepted as surface reactions, and the change in the oxide surface properties would significantly influence the overall reactivity (Anderson and Benjamin, 1990b; Meng and Letterman, 1993; Taujale et al., 2016; Huang et al., 2019a; Huang et al., 2019b). They might also substantially alter contaminants' solubility, toxicity, and bioavailability. Therefore, the redox reactions of Fe- and $\mathrm{Mn}$-oxides should be considered in many areas such as site remediation and chemical risk assessments.

$\mathrm{Fe}-$ and Mn-oxides typically exist in mixtures with other 
metal oxides (e.g., Al- and Si-oxides), metal ions (e.g., $\mathrm{Zn}^{2+}$ ), and/or ligands (e.g., NOM) in aquatic and soil environments. Despite years of investigation on the redox reactions of $\mathrm{Fe}$ - and Mn-oxides, to date, most previous studies have only focused on the roles of single metal oxides (Klausen et al., 1995; Charlet et al., 1998; Zhang and Huang, 2005; Huang et al., 2018). However, the surface and bulk properties of metal oxide mixtures behave largely differently from those of single metal oxides in natural aquatic environments (Anderson and Benjamin, 1990b). For instance, metal oxides might undergo heteroaggregation and influence the adsorption capacity through altering the number of surface sites and surface charges (Anderson and Benjamin, 1990a,b; Meng and Letterman, 1993; Huang et al., 2019a) and contaminant redox degradation (Taujale and Zhang, 2012; Huang et al., 2019a). Therefore, it is imperative to investigate oxide mixtures containing second metal oxides to enable more accurate prediction of the fate and transformation of numerous contaminants in the environment.

Natural organic matter (NOM) is a complex mixture of organic materials that vary from one source to another. It is ubiquitous in natural environments and has a large impact on the fate and transformation of contaminants (Davis, 1984; Redman et al., 2002). The adsorption of NOM onto $\mathrm{Fe}-$ and Mn-oxides can influence their physicochemical properties, e.g., colloidal stability or electrophoretic mobility (Gu et al., 1994). Thus, studies should be carried out to examine the interactions between NOM and metal oxides and to examine how NOM affects the redox reactivity of $\mathrm{Fe}$ - and Mn-oxides. This will enable the studied model systems to more accurately resemble actual environmental systems.

In this account, we focus on assessing recent developments and current understanding in the redox reactions of Fe- and Mn-oxides in complex systems, which will provide a bridge to connect the findings from simple model systems with those from natural environmental systems.

\section{Oxidative reaction in complex systems}

Manganese oxides have high reduction potentials and are able to effectively oxidize a wide range of organic contaminants, including phenols (Stone, 1987), anilines (Laha and Luthy, 1990), and other aromatic compounds (Zhang and Huang, 2003; Zhang and Huang, 2005; Zhang et al., 2008; Huang et al., 2018). Many studies have reported the surface involved reaction kinetics and mechanisms for oxidative degradation of aromatic compounds (ArXH) by single Mn oxides, as shown in Eqs. (1)(5) (Stone, 1987; Zhang et al., 2008; Huang and Zhang, 2019b).

$$
>\mathrm{Mn}^{\mathrm{IV}}+\mathrm{ArXH} \rightleftharpoons\left(\mathrm{Mn}^{\mathrm{IV}}, \mathrm{ArXH}\right)
$$

$$
\begin{gathered}
\left(>\mathrm{Mn}^{\mathrm{IV}}, \mathrm{ArXH}\right) \rightleftharpoons\left(\mathrm{Mn}^{\mathrm{III}}, \mathrm{ArX} \cdot\right)+\mathrm{H}^{+} \\
\left(>\mathrm{Mn}^{\mathrm{III}}, \mathrm{ArX} \cdot\right) \rightleftharpoons \mathrm{Mn}^{\mathrm{III}}+\mathrm{ArX} \cdot \\
>2 \mathrm{Mn}^{\mathrm{III}} \rightleftharpoons \mathrm{MnO}_{2}+>\mathrm{Mn}^{\mathrm{II}} \\
\mathrm{ArX} \cdot \rightleftharpoons \text { products }
\end{gathered}
$$

It is generally believed that either precursor complex formation (Eq. (1)) or electron transfer (Eq. (2)) is the ratelimiting step in the oxidative reactions of $\mathrm{MnO}_{2}$. These reactions typically occur on the oxide surface; thus, the physiochemical properties of $\mathrm{MnO}_{2}$, such as $\mathrm{Mn}(\mathrm{III})$ content, oxygen species, and surface area, can dramatically influence its oxidative reactivity (Nico and Zasoski, 2000; Simanova and Peña, 2015; Huang et al., 2018; Wang et al., 2019). Furthermore, the change on the oxide surface properties will likely affect either the precursor complex formation or the electron transfer and, hence, the overall reactivity (Fig. 1).

\subsection{Effects of metal ions on the oxidative reactivity}

Metal ions, such as $\mathrm{Mn}^{2+}, \mathrm{Ca}^{2+}, \mathrm{Ni}^{2+}, \mathrm{Cr}^{3+}$ and $\mathrm{Cu}^{2+}$, could decrease the oxidative reactivity (Klausen et al., 1997; Zhang and Huang, 2003; Barrett and McBride, 2005). (Zhang and Huang, 2003) showed that the inhibitory effect of metal ions deceased in the order: $\mathrm{Mn}^{2+}>\mathrm{Zn}^{2+}>\mathrm{Ca}^{2+}$. This is because the adsorption of these three metal ions on $\mathrm{MnO}_{2}$ decreased in the same order (Morgan and Stumm, 1964), inhibiting the reactivity. Furthermore, the adsorbed $\mathrm{Mn}^{2+}$ can block the reactive $\mathrm{Mn}$ (IV) surface sites, also decreasing the reactivity. Besides blocking reactive sites, the adsorbed $\mathrm{Mn}^{2+}$ can lower the reduction potential $(E)$ to slow the electron transfer in the oxidation of contaminants (Eq. (6)) (Li et al., 2008; Zhang et al., 2008):

$$
E=E_{0}-\frac{R T}{n F} \log \frac{\left[\mathrm{Mn}^{2+}\right]}{\left[\mathrm{H}^{+}\right]^{4}}
$$

where $E_{0}$ is the initial redox potential of manganese oxides; $R$ is the universal gas constant $(8.314 \mathrm{~J} / \mathrm{mol} / \mathrm{K}), T$ is the absolute temperature (Kelvin); $n$ is the number of electrons in for the reaction; and $F$ is the Faraday constant (96,485 C/mol).

Besides, some metal ions might even be involved in the redox reaction, such as $\mathrm{Cr}^{3+}$. The inhibitory effect of $\mathrm{Cr}^{3+}$ results from the reaction between $\mathrm{Cr}^{3+}$ and $\mathrm{Mn}(\mathrm{IV})$ to consume $\mathrm{Mn}(\mathrm{IV})$, as the simplest case shown in Eq. (7) (Eary and Rai, 1987).

$$
3 \mathrm{MnO}_{2}+2 \mathrm{H}_{2} \mathrm{O}+\mathrm{Cr}^{3+} \rightarrow 3 \mathrm{Mn}^{2+}+2 \mathrm{HCrO}_{4}^{-}
$$

However, Wang et al. discovered that $\mathrm{Ca}^{2+}$ and $\mathrm{Mg}^{2+}$ promoted the oxidation of fulvic acid by birnessite at the 


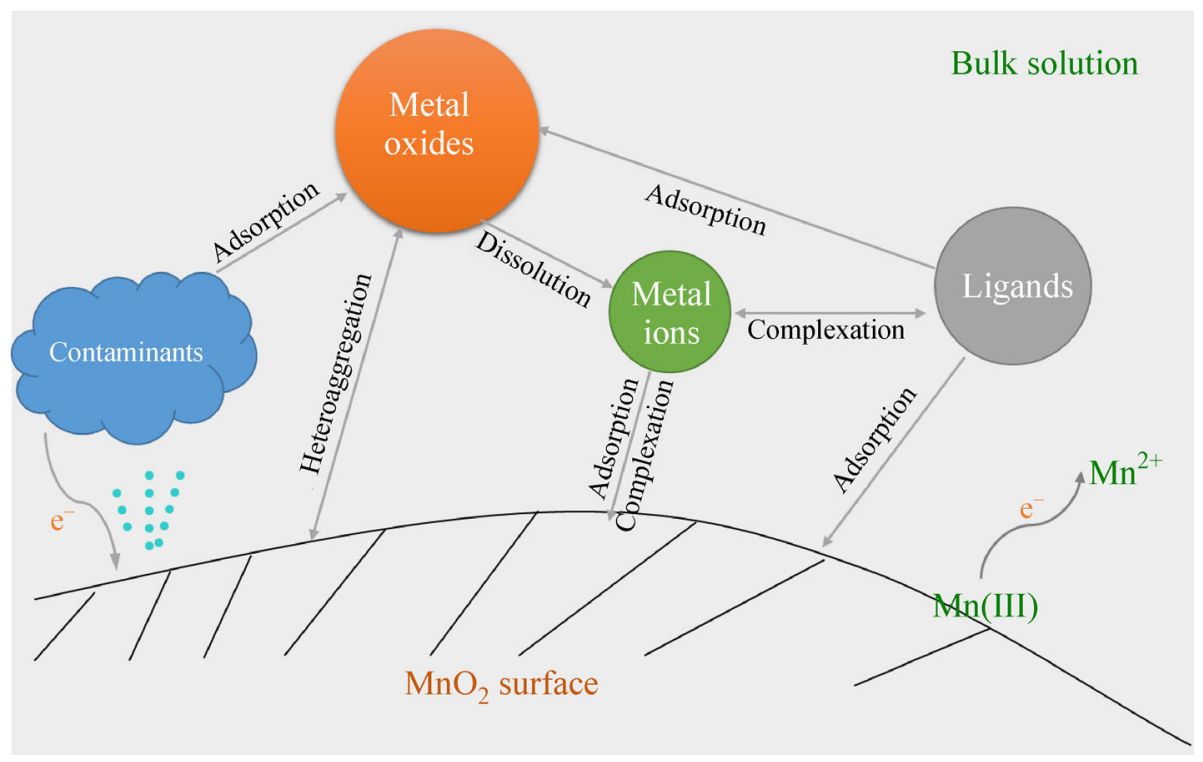

Fig. $1 \mathrm{MnO}_{2}$ surface-mediated oxidation of contaminants in complex systems.

early stage, but the mechanism remained unclear (Wang et al., 2019). It should be noted that studies have determined that different reactive sites, such as $\mathrm{Mn}(\mathrm{III}$, IV) in $\mathrm{MnO}_{2}$ sheets, $\mathrm{Mn}(\mathrm{III}, \mathrm{IV})$ at particle edges, and $\mathrm{Mn}$ (III) in interlayers, have different oxidizing abilities (Manceau et al., 1997; Yu et al., 2012). Mn(III) has been confirmed to be more reactive than Mn(IV) in the oxidation of bisphenol A (Huang et al., 2018), $\mathrm{Cr}^{3+}$ (Nico and Zasoski, 2000), and ammonia (Anschutz et al., 2005), but less reactive in the oxidation of As(III) (Zhu et al., 2009). Therefore, the interactions between metal ions and various reactive sites on $\mathrm{MnO}_{2}$ and how they influence the electron transfer warrant further research.

\subsection{Effects of ligands on the oxidative reactivity}

The effects of anionic ligands on the oxidative reactivity of manganese oxides can be ligand specific. Both inorganic (e.g., phosphate, sulfate, nitrate and chloride) and organic ligands (e.g., small ligands such as oxalic acid, citric acid, malic acid, and pyrophosphate (PP) and NOM) have been revealed to mostly decrease the oxidative reactivity of manganese oxides (Klausen et al., 1997; Ge and Qu, 2003; Zhang et al., 2008; Zhang et al., 2012). The inhibitory effects can be summarized as: (1) the ligands such as sulfate and nitrate compete with the chemicals for the binding sites on $\mathrm{MnO}_{2}$; and/or (2) the ligands such as oxalic acid and humic acid cause the reductive dissolution of $\mathrm{MnO}_{2}$ to release $\mathrm{Mn}^{2+}$ ions, which is a strong inhibitor, as mentioned in section 2.1 (Klausen et al., 1997; Zhang and Huang, 2003; Lu et al., 2011). $\mathrm{HPO}_{4}^{2-}$ has been reported to have a higher inhibitory effect than other inorganic ligands $\left(\mathrm{Cl}^{-}, \mathrm{NO}_{3}^{-}\right.$, and $\left.\mathrm{SO}_{4}^{2-}\right)$ because $\mathrm{HPO}_{4}^{2-}$ can firmly adsorb onto the $\mathrm{MnO}_{2}$ surface (Yao and Millero,
1996; Lu et al., 2011).

The addition of PP has been demonstrated to inhibit the $\mathrm{Cr}^{3+}$ oxidation by $\mathrm{MnO}_{2}$, because PP can solidly complex with $\mathrm{Mn}(\mathrm{III})$ to lower the $\mathrm{Mn}$ (III) availability (Nico and Zasoski, 2000). However, some researchers observed that PP enhanced the oxidation kinetics of bisphenol $\mathrm{A}$ and triclosan (Gao et al., 2018; Huang et al., 2018). This is because the abundance of $\mathrm{Mn}$ (III) is key in determining the oxidative reactivity, and PP can stabilize $\mathrm{Mn}$ (III) against disproportionation (Eq. (8)) (Huang et al., 2018). Further studies are therefore needed to elucidate the above different effects, such as the oxidative reactivity of $\mathrm{Mn}$ (III)-PP toward different chemicals. For instance, Mn(III)PP has been known to be able to oxidize some chemicals, such as phenols (Jiang et al., 2009; Jiang et al., 2010; Gao et al., 2018), but not others, such as carbamazepine and methyl p-tolyl sulfoxide (Gao et al., 2018).

$$
2 \mathrm{Mn}(\mathrm{III})+2 \mathrm{H}_{2} \mathrm{O} \rightarrow \mathrm{Mn}(\mathrm{II})+\mathrm{MnO}_{2}+4 \mathrm{H}^{+}
$$

Humic acid (HA) displayed either promotive or inhibitive effects on the oxidative reactivity of $\mathrm{MnO}_{2}$. On the one hand, HA exhibited a promotive effect in the degradation of contaminants including methylene blue, nonylhenol, 4-n-nonylphenol, 4-tert-octylphenol, and 17ßestradiol (Xu et al., 2008; Zhu et al., 2010; Lu and Gan, 2013). This is because HA can strongly complex with $\mathrm{Mn}$ (II) to decrease the adsorption of $\mathrm{Mn}^{2+}$ on $\mathrm{MnO}_{2}$ surfaces and hence eliminate the large inhibitory effect of the adsorbed $\mathrm{Mn}^{2+}$ (Xu et al., 2008; Zhu et al., 2010). On the other hand, $\mathrm{HA}$ inhibited the oxidative reactivity of $\mathrm{MnO}_{2}$ to degrade contaminants, such as 4-chloroaniline, $17 \beta$ estradiol and lincosamide, because it blocked the surface reactive sites to prevent the contaminants from being adsorbed and increased the extent of $\mathrm{MnO}_{2}$ dissolution 
(Klausen et al., 1997; Chen et al., 2010; Sun et al., 2016). HA is a complex compound containing various functional groups, which are known to exert different effects on redox reactions (Vindedahl et al., 2016). Therefore, more mechanistic investigation into the effect of the functional groups of $\mathrm{HA}$ on the oxidative reactivity of $\mathrm{MnO}_{2}$ is required to understand these different results.

\subsection{Effects of second metal oxides on the oxidative} reactivity

Metal oxides have been shown to influence the oxidative reactivity of $\mathrm{MnO}_{2}$, with different metal oxides exhibiting varying effects and mechanisms. These effects can be summarized as: (1) the interactions between the second metal oxides and $\mathrm{MnO}_{2}$ (e.g., heteroaggregation, surface complexation/precipitation) mostly inhibited the $\mathrm{MnO}_{2}$ reactivity; and (2) the second metal oxides might compete with $\mathrm{MnO}_{2}$ in adsorbing the chemical contaminants (Taujale and Zhang, 2012). For example, the inhibitory effect on the oxidative reactivity of $\mathrm{MnO}_{2}$ by second metal oxides deceased in the order: $\mathrm{Al}_{2} \mathrm{O}_{3}>\mathrm{SiO}_{2}>\mathrm{TiO}_{2}$ (Taujale and Zhang, 2012). This is because both $\mathrm{Al}_{2} \mathrm{O}_{3}$ and $\mathrm{SiO}_{2}$ can release $\mathrm{Al}$ and $\mathrm{Si}$ ions into the aqueous phase due to their dissolution. When examining the relative contribution of the released metal ions and metal oxide particles to the overall inhibitory effect, it was found that the released $\mathrm{Al}$ and Si ions had the dominant inhibitory effect (Fig. 2), mainly due to the surface complexation/precipitation of the ions on the surface of $\mathrm{MnO}_{2}$ (Taujale and Zhang, 2012). $\mathrm{TiO}_{2}$ only decreased the oxidative reactivity of $\mathrm{MnO}_{2}$ when a limited amount of triclosan was present, because a strong adsorption of triclosan on $\mathrm{TiO}_{2}$ inhibited the precursor complex formation between triclosan and the $\mathrm{MnO}_{2}$.

Iron oxides have also been reported to inhibit the oxidative reactivity of $\mathrm{MnO}_{2}$ (Zhang et al., 2015). The authors also attempted to investigate the relative contribu- tion of (1) soluble $\mathrm{Fe}^{3+}$ released from goethite dissolution and (2) aggregation of goethite particles to the overall reactivity. The released $\mathrm{Fe}^{3+}$ had limited inhibitory effect because of the poor solubility of iron oxides under a wide range of $\mathrm{pH}$ conditions, while the blocking of the surface reactive sites by the heteroaggregation between goethite and $\mathrm{MnO}_{2}$ (observed based on the sedimentation experiments and TEM images) was the major contributor to the decrease in the oxidative reactivity. The inhibitory effect further increased as the particle size decreased or the goethite loading increased.

Zhang's group then increased the complexity of the model systems and investigated the effect of NOM on the redox reactivity in ternary systems of two types of metal oxides plus NOM (Zhang et al., 2015; Taujale et al., 2016). To differentiate the effects due to NOM from those due to the second metal oxides, the parameter $\mathrm{P}$ was introduced (Eq. (9)). A P value of 1 suggests that the NOM does not have any additional effects on the reactivity, while a higher $\mathrm{P}$ value indicates higher oxidative reactivity of $\mathrm{MnO}_{2}$ and vice versa.

$$
P=\frac{k_{\text {with_NOM }}}{k_{\text {without_NOM }}} \times 100 \%
$$

where $k_{\text {with_NOM }}$ is the reaction rate constant of the ternary system (metal oxide $+\mathrm{MnO}_{2}+\mathrm{NOM}$ ), while $k_{\text {without }}$ NOM is the reaction rate constant of the binary system (metal oxide $+\mathrm{MnO}_{2}$ ).

Using the obtained $\mathrm{P}$ values, the authors revealed that higher concentrations of model NOM (Aldrich humic acid, alginate, or pyromellitic acid) in the ternary systems $\left(\mathrm{MnO}_{2}+\right.$ goethite $\left.+\mathrm{NOM}\right)$ had larger $\mathrm{P}$ values, indicating that the NOM promoted the oxidative reactivity of $\mathrm{MnO}_{2}$ in the ternary mixtures. This was ascribed to the observation that NOM enhanced the extent of homoaggregation within the iron oxides, which inhibited the extent of heteroaggregation between $\mathrm{MnO}_{2}$ and iron oxides (Zhang et al., 2015).

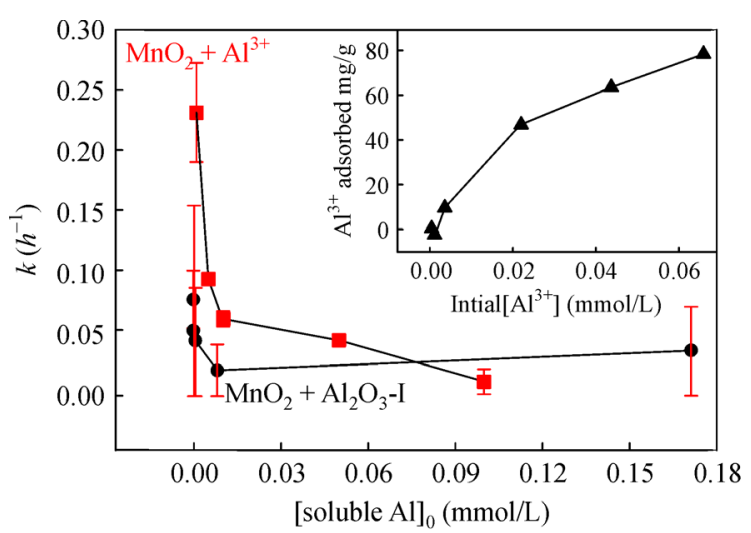

(a)

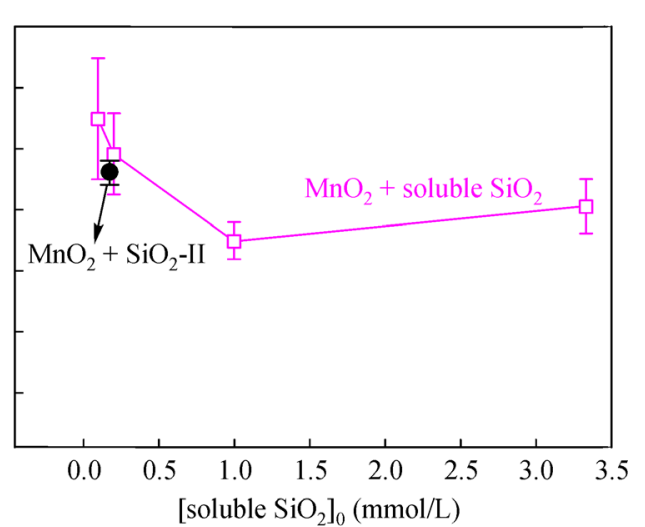

(b)

Fig. 2 Effect of (a) soluble $\mathrm{Al}$ ions and $\mathrm{Al}_{2} \mathrm{O}_{3}$ and (b) soluble silicate and $\mathrm{SiO}_{2}$ particle on the oxidation of triclosan by $\mathrm{MnO}_{2}(\mathrm{Taujale}$ and Zhang, 2012). 
The authors also studied another ternary system of $\mathrm{MnO}_{2}+\mathrm{Al}_{2} \mathrm{O}_{3}+\mathrm{HA}$ and found that the reactivity of $\mathrm{MnO}_{2}+\mathrm{Al}_{2} \mathrm{O}_{3}+\mathrm{HA}$ was different from that of $\mathrm{MnO}_{2}+$ $\mathrm{Al}$ ions $+\mathrm{HA}$, indicating that $\mathrm{Al}$ ions surprisingly did not play a dominant role in influencing the oxidative reactivity in the system of $\mathrm{MnO}_{2}+\mathrm{Al}_{2} \mathrm{O}_{3}+\mathrm{HA}$. This is drastically different from the binary system of $\mathrm{MnO}_{2}+\mathrm{Al}_{2} \mathrm{O}_{3}$, as mentioned above, because HA inhibited the dissolution of $\mathrm{Al}_{2} \mathrm{O}_{3}$ (Zhang et al., 2015). Therefore, the change in the heteroaggregation pattern between $\mathrm{Al}_{2} \mathrm{O}_{3}$ and $\mathrm{MnO}_{2}$ (based on sedimentation experiments) upon the addition of HA was of great importance in affecting the oxidative reactivity in the ternary systems. Similar results were also obtained for the ternary systems of $\mathrm{MnO}_{2}+\mathrm{Al}_{2} \mathrm{O}_{3}+$ alginate and $\mathrm{MnO}_{2}+\mathrm{Al}_{2} \mathrm{O}_{3}+$ pyromellitic acid (Taujale et al., 2016), suggesting that this may be a general phenomenon in similar ternary mixtures.

\subsection{Oxidative reactivity of iron oxides in complex systems}

Besides $\mathrm{MnO}_{2}$, iron oxides have been used to oxidize a wide range of contaminants, including phenols, aniline, hydroquinones and fluoroquinolone (LaKind and Stone, 1989; Zhang and Huang, 2007). Compared with $\mathrm{MnO}_{2}$, iron oxides generally have lower oxidizing ability, with the reduction potentials $0.66-0.67 \mathrm{~V}$ vs. $1.23 \mathrm{~V}$ for $\mathrm{MnO}_{2}$ (Eqs. (10) and 11) (LaKind and Stone, 1989).

$$
\alpha-\mathrm{FeOOH}+3 \mathrm{H}^{+}+\mathrm{e}^{-} \rightarrow \mathrm{Fe}^{2+}+2 \mathrm{H}_{2} \mathrm{O}, E^{0}=0.67 \mathrm{~V}
$$

$$
\alpha-\mathrm{Fe}_{2} \mathrm{O}_{3}+6 \mathrm{H}^{+}+2 \mathrm{e}^{-} \rightarrow 2 \mathrm{Fe}^{2+}+3 \mathrm{H}_{2} \mathrm{O}, E^{0}=0.66 \mathrm{~V}
$$

Similar to $\mathrm{MnO}_{2}$, the oxidation of iron oxides is also considered as surface-related (LaKind and Stone, 1989; Zhang and Huang, 2007; Zhang et al., 2019). Therefore, the addition of metal ions, ligands and second metal oxides can influence the surface properties of iron oxides and thus their reaction kinetics. Sulfate, phosphate and $\mathrm{Ca}^{2+}$ at low concentrations $([$ sulfate $]<0.1 \mathrm{mmol} / \mathrm{L}$, [phosphate] $=$ $0.001-1 \mathrm{mmol} / \mathrm{L}$, and $\left[\mathrm{Ca}^{2+}\right]=0.01-10 \mathrm{mmol} / \mathrm{L}$ ) exhibited a negligible effect on the oxidative reactivity of goethite, but decreased the oxidative reactivity at high concentrations ([sulfate] $>1 \mathrm{mmol} / \mathrm{L}$ ) (LaKind and Stone, 1989). Such an inhibitory effect is because these ligands and metal ions might block the surface reactive sites toward the contaminants. This result is different from a later study on the effect of phosphate on the oxidative degradation of anthraquinone-2,6-disulfonate $\left(\mathrm{AH}_{2} \mathrm{DS}\right)$ by hematite (Liu et al., 2007). Here, phosphate was demonstrated to significantly inhibit the oxidative reactivity of hematite due to its strong complexation with hematite (Liu et al., 2007). In addition, $\mathrm{Fe}^{2+}$ has been reported to decrease the oxidative degradation of anthraquinone-2,6-disulfonate $\left(\mathrm{AH}_{2} \mathrm{DS}\right)$ by hematite through two mechanisms: (1) $\mathrm{Fe}^{2+}$ competes with $\mathrm{AH}_{2} \mathrm{DS}$ for the surface reactive sites on the hematite surface; and (2) $\mathrm{Fe}^{2+}$ as a reaction product decreases the Gibbs free energy of the reaction (Eq. (12)) (Liu et al., 2007).

$$
\mathrm{AH}_{2} \mathrm{DS}^{2-}+\mathrm{Fe}_{2} \mathrm{O}_{3}+4 \mathrm{H}^{+}=\mathrm{AQDS}^{2-}+2 \mathrm{Fe}^{2+}+3 \mathrm{H}_{2} \mathrm{O}
$$

In a recent work, Zhang et al. (2019) attempted to elucidate the interactions between goethite and $\mathrm{Al}_{2} \mathrm{O}_{3}$, and to understand how the interactions affected the oxidative reactivity of goethite (Zhang et al., 2019). Not surprisingly, $\mathrm{Al}_{2} \mathrm{O}_{3}$ exhibited a strong inhibitory effect on the oxidative degradation of hydroquinone by goethite at $\mathrm{pH} 3$. However, unlike the binary system of $\mathrm{MnO}_{2}+\mathrm{Al}_{2} \mathrm{O}_{3}$ (Taujale and Zhang, 2012), the release of $\mathrm{Al}$ ions due to $\mathrm{Al}_{2} \mathrm{O}_{3}$ dissolution did not affect the reactivity of goethite. Instead, the amount of $\mathrm{Fe}^{3+}$ released from the goethite dissolution at $\mathrm{pH} 3$ exhibited a good linear correlation with the obtained reaction rate, indicating that the inhibitory effect was due to the decreasing amount of $\mathrm{Fe}^{3+}$ in the presence of $\mathrm{Al}_{2} \mathrm{O}_{3}$. This difference pointed to the important role of solution conditions such as $\mathrm{pH}$ and the types of oxides in affecting the interactions between oxides. It also serves as a reminder to future researchers that when studying complex mixtures, we should always keep the complexity in mind and carefully consider all possible reactions and reaction conditions.

\section{Reductive reactions in complex systems}

Regarding reductive transformation of contaminants, surface associated $\mathrm{Fe}(\mathrm{II})$ has been well documented to be a major reductant and can reduce a wide range of contaminants, including U(VI) (Liger et al., 1999), technetium (Peretyazhko et al., 2009), nitroaromatic compounds (Klausen et al., 1995), $\mathrm{CCl}_{4}$ (Amonette et al., 2000), polyhalogenated methanes (Pecher et al., 2002), and $\mathrm{N}-\mathrm{O}$ containing compounds ( $\mathrm{Li}$ et al., 2019).

Until now, the reasons on how iron oxides significantly enhanced the reductive reactivity of Fe(II) are still not well understood. Previous studies proposed that it might result from the sorbed $\mathrm{Fe}(\mathrm{II})$ coordinated with $\mathrm{O}$-donor atoms on the surface of iron oxides, similar to hydroxylated Fe(II) species in aqueous solution (Wehrli et al., 1989). Surface complexation modeling has been employed to examine the formed sorbed $\mathrm{Fe}(\mathrm{II})$ species, and $\mathrm{Fe}^{\mathrm{III}} \mathrm{OFe} \mathrm{e}^{\mathrm{II}} \mathrm{OH}$ was believed to be the dominant reactive species (Charlet et al., 1998; Liger et al., 1999). However, it has been shown that stable sorbed Fe(II) did not exist because of fast electron transfer between the sorbed Fe(II) and iron oxides (Williams and Scherer, 2004; Larese-Casanova and Scherer, 2007). Moreover, negligible reduction of nitrobenzene was observed when aqueous Fe(II) was removed from the solution, indicating that aqueous Fe(II) was also 
involved in the reductive reaction (Williams and Scherer, 2004). In addition, Yanina and Rosso (2008) demonstrated a critical role of electron transport through the bulk solid in interfacial redox reactivity (Yanina and Rosso, 2008). Therefore, Gorski and Scherer proposed a revised conceptual model for Fe(II) adsorption onto Fe(III) oxides based on a semiconductor model (Becker et al., 2001; Park and Dempsey, 2005; Barnes et al., 2009; Gorski and Scherer, 2011). In the model, electrons from the sorbed Fe (II) are transferred to the bulk iron oxide particles and effectively doped the iron oxides (considered as semiconductors) with additional electrons, part of which are eventually transferred to reduce the contaminants.

Different factors, such as $\mathrm{pH}$, the amount of $\mathrm{Fe}(\mathrm{II})$ sorbed, and surface sorbed Fe(II) species, have been shown to influence the reactivity (Elsner et al., 2004; Zhang and Weber, 2013; Huang et al., 2019a; Huang et al., 2019b). Typically, higher amount of sorbed Fe(II) would result in higher reactivity. Despite the large volume of research that focused on simple model systems containing an $\mathrm{Fe}(\mathrm{III})$ mineral and soluble $\mathrm{Fe}^{2+}$, which fails to represent actual environmental conditions, there has been only a few studies investigating the reductive reactivity of $\mathrm{Fe}^{2+} /$ iron oxides in complex systems (Fig. 3).

\subsection{Effect of metal ions on the reductive reactivity}

Metal ions can influence the reductive reactivity of $\mathrm{Fe}^{2+}$ complexed with iron oxides. For example, $\mathrm{Co}^{2+}, \mathrm{Ni}^{2+}$, and $\mathrm{Zn}^{2+}$ exhibited inhibitory effects on the reductive reactivity of $\mathrm{Fe}^{2+}$ treated goethite, which was ascribed to the competitive adsorption between these metal ions and $\mathrm{Fe}^{2+}$ (Maithreepala and Doong, 2004). However, $\mathrm{Cu}^{2+}$ demonstrated a significant enhancement in the reductive reactivity, because $\mathrm{Cu}(\mathrm{I})$, reduced from $\mathrm{Cu}^{2+}$ by $\mathrm{Fe}^{2+}$, acted as an additional reductant to enhance the reaction rate (Maithreepala and Doong, 2004). In addition, the reductive reactivity of $\mathrm{Fe}^{2+}$ /goethite might vary with the amount of $\mathrm{Cu}^{2+}$ added. The reactivity increased in the presence of $\mathrm{Cu}^{2+}$ with its concentration lower than $0.375 \mathrm{mmol} / \mathrm{L}$, but decreased when the $\mathrm{Cu}^{2+}$ concentration was between 0.375 and $1 \mathrm{mmol} / \mathrm{L}$ (Tao et al., 2013). The authors believed that the reactivity was related to the density of the sorbed Fe(II) on goethite, and the addition of $\mathrm{Cu}^{2+}$ increased it when $\left[\mathrm{Cu}^{2+}\right]$ was lower than $0.375 \mathrm{mmol} / \mathrm{L}$, while decreased when $\left[\mathrm{Cu}^{2+}\right]$ was higher than $0.375 \mathrm{mmol} / \mathrm{L}$. However, the mechanism on how the addition of $\mathrm{Cu}^{2+}$ influenced the density of sorbed $\mathrm{Fe}(\mathrm{II})$ is not clear yet.

\subsection{Effect of ligands on the reductive reactivity}

Anionic ligands can also influence the reductive reactivity of $\mathrm{Fe}^{2+}$ /iron oxides. One of the widely studied ligands is NOM, which exhibited either promotive or inhibitive effects on the reductive reactivity of $\mathrm{Fe}^{2+}$ /iron oxides (Colón et al., 2008; Zhang and Weber, 2009; Vindedahl et al., 2016). On the one hand, NOM can enhance the reactivity. (Zhang and Weber, 2009) verified that the reduced Suwannee River NOM and reduced juglone enhanced the reductive degradation of 4-cyano-4'-aminoazobenzene by $\mathrm{Fe}^{2+} /$ goethite, because they functioned as electron shuttles and were able to reduce the goethite

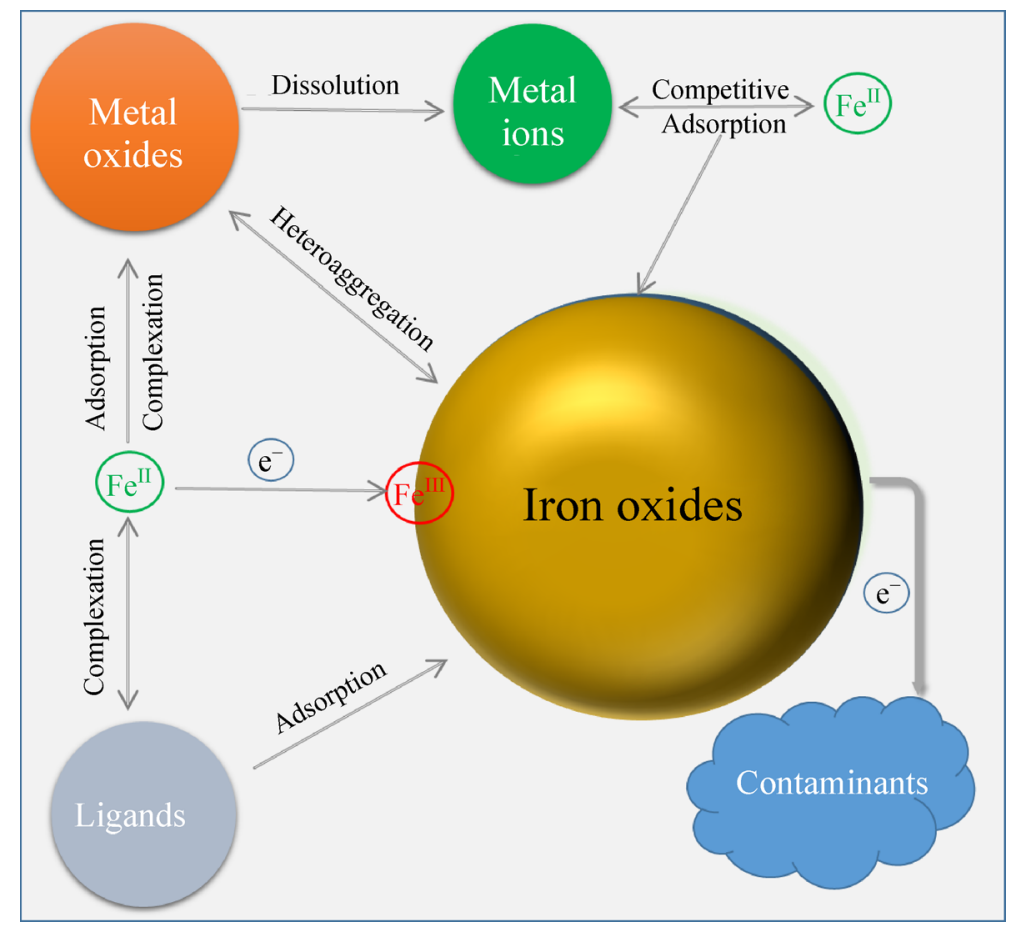

Fig. 3 Reduction of contaminants by Fe(II)/iron oxides in complex systems. 
surface to increase the formation of surface sorbed Fe(II).

On the other hand, NOM can decrease the reductive reactivity due to multiple reasons (Colón et al., 2008; Vindedahl et al., 2016). First, the reduction rates and capacity of the system having Suwannee river humic acid (SRHA) added after Fe(II) was equilibrated with goethite (G/Fe(II)/SRHA) was lower than that having Fe(II) added after SRHA was equilibrated with goethite (G/SRHA/Fe (II)). This might be ascribed to (1) the oxidation and/or complexation of the surface-sorbed Fe(II) by SRHA; and/ or (2) SRHA blocked electron transfer from the surface sorbed Fe(II) to the chemical probes (Colón et al., 2008). Second, compared with (Colón et al., 2008), NOM in the study of (Zhang and Weber, 2009) had been chemically reduced, so the oxidation state of the NOM should be the main reason for the different effects observed in these two studies. Third, the characteristics of NOM can also influence the reactivity. Vindedahl et al. discovered that the increased molecular weight and nitrogen, carbon, and aromatic contents in NOM enhanced the reductive degradation rates, whereas increased carboxyl concentration and oxygen, heteroaliphatic, and aliphatic contents decreased the reactivity. In addition, the authors found that the amount of $\mathrm{Fe}$ (II) sorbed on goethite was not affected by NOM and the change in the aggregation state of goethite was not the reason for the reactivity decrease. Thus, they attributed the inhibitory effect of NOM to (1) changes in surface $\mathrm{Fe}(\mathrm{II})$ reactive species and (2) blocking of electron transfer to goethite surface (Vindedahl et al., 2016). Given the complexity of NOM effects, future research should focus on NOM of different types, origins, oxidation states, etc.

To better understand the formation of surface sorbed $\mathrm{Fe}$ (II) species on iron oxides in the present of ligands and to elucidate how these species affect the reductive reactivity of $\mathrm{Fe}^{2+}$ /iron oxides, surface complexation modeling (SCM) has been employed to investigate the formation of surface $\mathrm{Fe}(\mathrm{II})$ species in the presence of phthalic acid (Huang et al., 2019b). As shown in Fig. 4, besides the

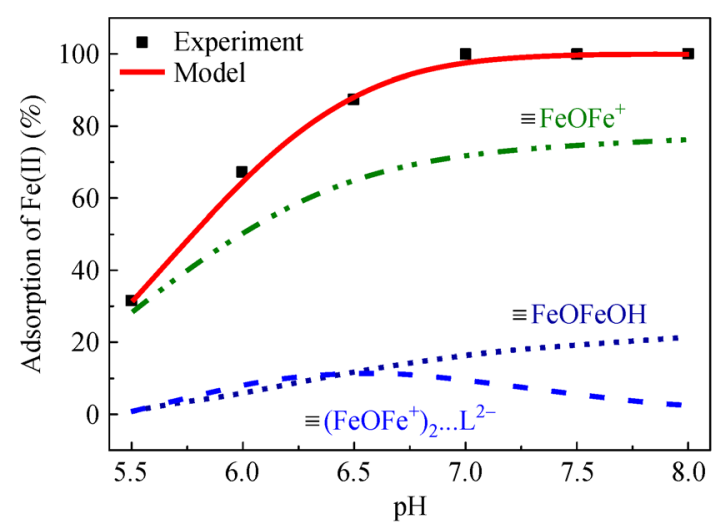

(a) two major binary $\mathrm{Fe}(\mathrm{II})$ species $\left(\equiv \mathrm{FeOFe}^{+}\right.$and $\equiv \mathrm{FeO}$ $\mathrm{FeOH}$ ), one additional outer-spheric ternary species $\left(\left(\equiv \mathrm{FeOFe}^{+}\right)_{2 \ldots} \mathrm{L}^{2-}\right)$ formed in the presence of phthalic acid, which might partly result in the reactivity decrease. In addition, the decrease in the amount of reactive $\mathrm{Fe}$ (II) monohydroxo surface species $(\equiv \mathrm{FeOFeOH})$ was another reason for the lower reactivity. However, the above two reasons only accounted for part of the reactivity decrease, thus, the authors proposed two additional mechanisms: (1) phthalic acid might have blocked the more reactive sites on the goethite surface; and (2) phthalic acid might have blocked the electron transfer from $\mathrm{Fe}$ (II) to the conduction band of iron oxides and then to the contaminant.

In addition, Latta et al. observed that some anions $\left(\mathrm{PO}_{4}^{3-}, \mathrm{CO}_{3}^{2-}, \mathrm{SiO}_{4}^{4-}\right.$, and $\left.\mathrm{HA}\right)$ did not inhibit electron transfer between $\mathrm{Fe}^{2+}$ and goethite (Latta et al., 2012). Note that although electron transfer in that study was not completely inhibited, it might still have slowed down, which might have influenced the reductive transformation of various contaminants. In fact, Jones et al. demonstrated that $\mathrm{Si}$ and NOM decreased the rate and extent of isotope exchange between $\mathrm{Fe}^{2+}$ and iron oxides (Jones et al., 2009). Thus, it is necessary to examine the effect of common anionic ligands on the electron transfer between $\mathrm{Fe}^{2+}$ and iron oxides in future studies.

\subsection{Effect of second metal oxides on the reductive reactivity}

Besides NOM and small anionic ligands, the effect of second metal oxides on the reductive reactivity should also be considered. Along this line, Huang et al. have investigated the effects of $\mathrm{SiO}_{2}$ and $\mathrm{TiO}_{2}$ on the reductive reactivity of $\mathrm{Fe}^{2+}$ /goethite (Huang et al., 2019a). For $\mathrm{SiO}_{2}$, it significantly lowered the reductive reactivity of $\mathrm{Fe}^{2+} /$ goethite. Then, the authors found that the inhibitory effect by the $\mathrm{Si}$ ions (released from $\mathrm{SiO}_{2}$ dissolution) was quite comparable to that by the $\mathrm{SiO}_{2}$ particles, suggesting that the aqueous $\mathrm{Si}$ ions were the main reason for the overall inhibitory effect. Soluble Si ions might have competed

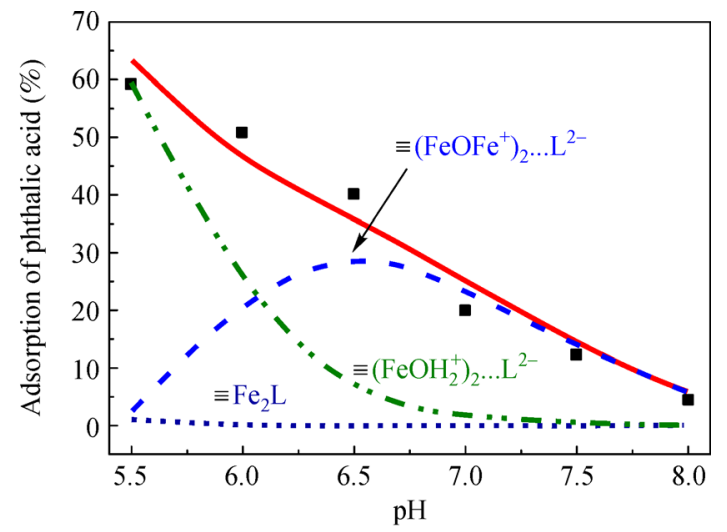

(b)

Fig. 4 Triple layer modeling results for $\mathrm{Fe}^{2+}$ and phthalic acid (L) adsorption onto goethite in the ternary systems (Huang et al., 2019a). 
with $\mathrm{Fe}^{2+}$ to decrease the amount of $\mathrm{Fe}$ (II) sorbed, subsequently leading to the reactivity decrease.

Unlike $\mathrm{SiO}_{2}, \mathrm{TiO}_{2}$ surprisingly dramatically enhanced the reactivity, which was ascribed to interparticle electron transfer, that is, the electrons from $\mathrm{Fe}$ (II) went through the conduction band of $\mathrm{TiO}_{2}$ to that of goethite before reaching the contaminant (Huang et al., 2019a). The reactivity of $\mathrm{Fe}^{2+} /$ goethite $+\mathrm{TiO}_{2}$ system depended on the types of $\mathrm{TiO}_{2}$, with the reaction rate decreased in the order: rutile $>\mathrm{TiO}_{2}-\mathrm{P} 25>$ anatase. This order agreed well with the conduction band energy of $\mathrm{TiO}_{2}$, suggesting that the conduction band energy of semiconductor minerals might have affected the electron transfer. Then, the authors utilized a dialysis bag to prevent the direct contact between goethite and $\mathrm{TiO}_{2}$, and found that the promoting effect of $\mathrm{TiO}_{2}$ disappeared. Based on the above results, interparticle electron transfer was for the first time proposed to occur under dark conditions that enhanced the reductive reactivity. However, additional work is needed to further elucidate the interactions and mechanisms of interparticle electron transfer within different oxide mixtures, especially between iron oxides and titanium dioxides, and how such a new mechanism can be applied to develop new site remediation technologies.

Besides metal oxides, clay minerals in soils and sediments also coexist with iron oxides (Tombácz et al., 2001; Dimirkou et al., 2002). Among them, kaolinite $\left.\left(\mathrm{Al}_{2} \mathrm{Si}_{2} \mathrm{O}_{5}(\mathrm{OH})_{4}\right)\right)$ has been demonstrated to decrease the reductive reactivity, due to the competitive adsorption of $\mathrm{Fe}^{2+}$ and the $\mathrm{Al} / \mathrm{Si}$ ions released from kaolinite dissolution (Strehlau et al., 2017). Al and $\mathrm{Si}$ ions can also be incorporated in goethite or on its surface, resulting in the reactivity decrease.

Note that dynamic light scattering (DLS), sedimentation experiments, and electron microscopy (SEM and TEM) have been frequently used to study the size and heteroaggregation of particles. DLS can only be used in dilute suspensions $(<0.2 \mathrm{~g} / \mathrm{L})$ for sub-micron particles (Cwiertny et al., 2008; Zhang et al., 2015). For more concentrated suspensions and larger particles, sedimentation experiments have been employed to understand the extents of heteroaggregation of metal oxides (Zhang et al., 2015; Taujale et al., 2016; Huang et al., 2019a). During such experiments, sedimentation of mixed metal oxides was monitored at a certain wavenumber as a function of time with UV-vis spectrophotometry. Here, instead of measuring the adsorption of light, the scattering of light was actually obtained (Huang et al., 2019a); and the faster the sedimentation rate, the larger the formed aggregates in the suspension.

In addition, electron microscopy, such as SEM and TEM, has been used to observe the heteroaggregation and homoaggregation states of mixed metal oxides. Compared with traditional SEM and TEM that are for dry samples only, cryo-TEM/SEM have unique advantages because they are able to provide images of in situ aggregates at specific times. For example, cryo-TEM has been used to examine the aggregation state of goethite in the mixture of goethite and kaolinite (Strehlau et al., 2017). The cryoTEM image (Fig. 5) surprisingly showed that the goethite was in homoaggregates, independent of the kaolinite loading, even though the surface charges are opposite for goethite (positive) and kaolinite (negative). The phenomenon indicated that the inhibition of the reductive reactivity of $\mathrm{Fe}(\mathrm{II}) /$ goethite by kaolinite was not because of heteroaggregation in the aqueous phase (Strehlau et al., 2017). However, the reasons why there is no heteroaggregation between goethite and kaolinite are not clear.

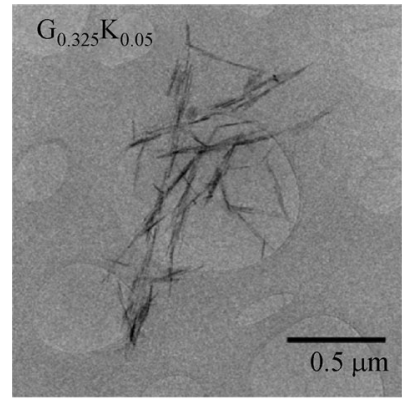

(a)

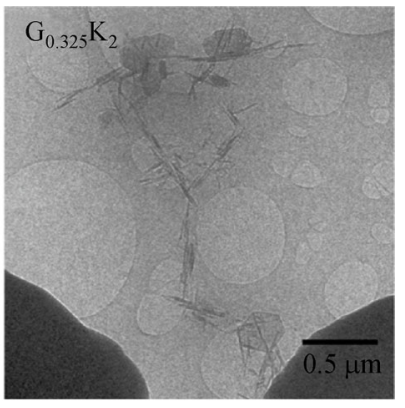

(b)
Fig. 5 Cryo-TEM images of (a) $0.325 \mathrm{~g} / \mathrm{L}$ goethite (G) $+0.05 \mathrm{~g} / \mathrm{L}$ kaolinite $(\mathrm{K})$ suspension and (b) $0.325 \mathrm{~g} / \mathrm{L} \mathrm{G}+2 \mathrm{~g} / \mathrm{L}$ K suspension (Strehlau et al., 2017).

\subsection{Reductive reactivity in sediments}

Metal oxides are an important composition of soil and sediments. Several studies have investigated the reductive reactivity in sediments. Zhang and Weber examined the reductive reactivity of 21 natural sediments and attempted to correlate the sediment physicochemical properties, including BET surface area, cation-exchange capacity, texture, Fe speciation and composition, and organic carbon content, to their reductive reactivity (Zhang and Weber, 2013). Based on the cluster and regression analysis, the authors revealed that surface-associated $\mathrm{Fe}^{2+}$ as well as reduced DOC played a deciding role in the reductive reactivity of the anaerobic sediments. Other researchers have also conducted field experiments in a landfill leachate plume of a sandy aquifer to elucidate the contribution of various reductants to the overall reactivity (Rügge et al., 1998). They found that the surface sorbed Fe(II) on iron (hydr)oxides was the dominant reductant, even though DOM had a high concentration. One likely reason is that the DOM in the plume was mostly oxidized, and hence lacking the reducing ability. Despite the above efforts, the relative contribution of $\mathrm{Fe}^{2+}$ associated reductants and DOM (and possibly other reductants) to the overall reactivity of actual sediment systems is still mostly unclear, which warrants further research. 


\section{Future outlook}

The knowledge of the redox reactions of $\mathrm{Fe}-$ and $\mathrm{Mn}$ oxides in different systems is important to understand biogeochemical processes. Future research focusing on examining their reactivity in complex systems is necessary, as briefly summarized below:

First, the redox reactions of $\mathrm{Fe}$ - and Mn-oxides in complex systems are remarkably different from simple model system. To better simulate actual environmental systems, it is necessary to increase the complexity of model systems sequentially (from binary systems to ternary systems, then to more complex systems) to study the redox reactions of organic contaminants with various functional groups and of different inorganic contaminants, which will be important for conducting site-specific chemical exposure assessments.

Second, most of previous studies only focused on $\delta$ $\mathrm{MnO}_{2}$; this is especially the case in complex systems (Taujale and Zhang, 2012; Zhang et al., 2015; Taujale et al., 2016). However, there are different phase structures of $\mathrm{MnO}_{2}$, such as $\alpha-, \beta-, \gamma-, \delta$-, and $\lambda-\mathrm{MnO}_{2}$, and they demonstrated various catalytic and direct oxidative reactivities due to different surface and structural properties (Meng et al., 2014; Huang et al., 2018; Huang and Zhang, 2019a). Therefore, it will be interesting and useful to investigate the effects of metal ions, ligands and second metal oxides on the oxidative reactivity of these $\mathrm{MnO}_{2}$ of different phase structures.

Third, despite some studies reporting that semiconductor minerals play an essential role in the reductive reactivity of Fe oxides (Taylor et al., 2017; Huang et al., 2019a), how electrons are transferred from these semiconductor minerals to Fe oxides is still not clear. For example, how is the sorbed $\mathrm{Fe}(\mathrm{II})$ distributed in complex systems containing iron oxides and other semiconductor minerals? What properties of semiconductors are most influential in affecting the reactivity of $\mathrm{Fe}(\mathrm{II}) / \mathrm{Fe}$ oxides? With further investigation, it is possible to identify the types of semiconductor minerals that can promote the rates of electron transfer in complex systems.

Fourth, besides surface sorbed Fe(II), some iron minerals, such as magnetite and green rust, contain both $\mathrm{Fe}(\mathrm{II})$ and $\mathrm{Fe}$ (III) and have been demonstrated to reduce a number of contaminants (Génin et al., 2001; Gorski and Scherer, 2009). Many factors have been shown to influence the reactivity, including particle size, the ratio of $\mathrm{Fe}(\mathrm{II}) / \mathrm{Fe}$ (III), and water composition (e.g., pH) (Danielsen and Hayes, 2004; Vikesland et al., 2007; Gorski and Scherer, 2009). However, there are only few studies on the reductive reactivity of these mixed-valent iron minerals in complex systems (Swindle et al., 2015; Sundman et al., 2017). Therefore, investigating the effects of metal ions, ligands and second metal oxides on the reactivity of mixed-valent iron minerals is also necessary to improve site remediation technologies and risk assessments.

Finally, as mentioned in Introduction, numerous contaminants can undergo redox reactions, which can influence their toxicity, solubility and bioavailability in the environment. Many studies on complex systems only focused on the abatement of parent compounds without considering the intermediates or final products, which requires further research.

Acknowledgements This material is based upon work supported by the National Science Foundation under Grants CBET-1762691 and CHE1808406 to H. Zhang. The authors are thankful to Dr. Zheng Li at University of Washington for the assistance for TOC drawing.

Open Access This article is licensed under a Creative Commons Attribution 4.0 International License, which permits use, sharing, adaptation, distribution and reproduction in any medium or format, as long as you give appropriate credit to the original author(s) and the source, provide a link to the Creative Commons licence, and indicate if changes were made. The images or other third party material in this article are included in the article's Creative Commons licence, unless indicated otherwise in a credit line to the material. If material is not included in the article's Creative Commons licence and your intended use is not permitted by statutory regulation or exceeds the permitted use, you will need to obtain permission directly from the copyright holder. To view a copy of this licence, visit http://creativecommons.org/licenses/by/4.0/.

\section{References}

Amonette J E, Workman D J, Kennedy D W, Fruchter J S, Gorby Y A (2000). Dechlorination of carbon tetrachloride by Fe(II) associated with goethite. Environmental Science \& Technology, 34(21): 46064613

Anderson P R, Benjamin M M (1990a). Modeling adsorption in aluminum-iron binary oxide suspensions. Environmental Science \& Technology, 24(10): 1586-1592

Anderson P R, Benjamin M M (1990b). Surface and bulk characteristics of binary oxide suspensions. Environmental Science \& Technology, 24(5): 692-698

Anschutz P, Dedieu K, Desmazes F, Chaillou G (2005). Speciation, oxidation state, and reactivity of particulate manganese in marine sediments. Chemical Geology, 218(3-4): 265-279

Barnes A, Sapsford D J, Dey M, Williams K P (2009). Heterogeneous Fe (II) oxidation and zeta potential. Journal of Geochemical Exploration, 100(2-3): 192-198

Barrett K A, McBride M B (2005). Oxidative degradation of glyphosate and aminomethylphosphonate by manganese oxide. Environmental Science \& Technology, 39(23): 9223-9228

Becker U, Rosso K M, Hochella M F Jr (2001). The proximity effect on semiconducting mineral surfaces: A new aspect of mineral surface reactivity and surface complexation theory? Geochimica et Cosmochimica Acta, 65(16): 2641-2649

Borch T, Kretzschmar R, Kappler A, Cappellen P V, Ginder-Vogel M, Voegelin A, Campbell K (2010). Biogeochemical redox processes and their impact on contaminant dynamics. Environmental Science \& Technology, 44(1): 15-23

Charlet L, Silvester E, Liger E (1998). N-compound reduction and 
actinide immobilisation in surficial fluids by $\mathrm{Fe}(\mathrm{II})$ : The surface $\mathrm{Fe}^{\mathrm{III}} \mathrm{OFe}^{\mathrm{II}} \mathrm{OH}^{\circ}$ species as major reductant. Chemical Geology, 151(14): $85-93$

Chen W R, Ding Y, Johnston C T, Teppen B J, Boyd S A, Li H (2010). Reaction of lincosamide antibiotics with manganese oxide in aqueous solution. Environmental Science \& Technology, 44(12): 4486-4492

Colón D, Weber E J, Anderson J L (2008). Effect of natural organic matter on the reduction of nitroaromatics by $\mathrm{Fe}(\mathrm{II})$ species. Environmental Science \& Technology, 42(17): 6538-6543

Cwiertny D M, Handler R M, Schaefer M V, Grassian V H, Scherer M M (2008). Interpreting nanoscale size-effects in aggregated Fe-oxide suspensions: Reaction of $\mathrm{Fe}(\mathrm{II})$ with goethite. Geochimica et Cosmochimica Acta, 72(5): 1365-1380

Danielsen K M, Hayes K F (2004). pH dependence of carbon tetrachloride reductive dechlorination by magnetite. Environmental Science \& Technology, 38(18): 4745-4752

Davis J A (1984). Complexation of trace metals by adsorbed natural organic matter. Geochimica et Cosmochimica Acta, 48(4): 679-691

Dimirkou A, Ioannou A, Doula M (2002). Preparation, characterization and sorption properties for phosphates of hematite, bentonite and bentonite-hematite systems. Advances in Colloid and Interface Science, 97(1-3): 37-61

Eary L E, Rai D (1987). Kinetics of chromium(III) oxidation to chromium(VI) by reaction with manganese dioxide. Environmental Science \& Technology, 21(12): 1187-1193

Elsner M, Schwarzenbach R P, Haderlein S B (2004). Reactivity of Fe (II)-bearing minerals toward reductive transformation of organic contaminants. Environmental Science \& Technology, 38(3): 799-807

Gao Y, Jiang J, Zhou Y, Pang S Y, Jiang C, Guo Q, Duan J B (2018). Does soluble $\mathrm{Mn}$ (III) oxidant formed in situ account for enhanced transformation of triclosan by $\mathrm{Mn}(\mathrm{VII})$ in the presence of ligands? Environmental Science \& Technology, 52(8): 4785-4793

Ge J, Qu J (2003). Degradation of azo dye acid red B on manganese dioxide in the absence and presence of ultrasonic irradiation. Journal of Hazardous Materials, 100(1-3): 197-207

Génin J M R, Refait P, Bourrié G, Abdelmoula M, Trolard F (2001). Structure and stability of the Fe (II)-Fe (III) green rust "fougerite" mineral and its potential for reducing pollutants in soil solutions. Applied Geochemistry, 16(5): 559-570

Gorski C, Scherer M(2011). $\mathrm{Fe}^{2+}$ sorption at the $\mathrm{Fe}$ oxide-water interface: A revised conceptual framework. In: Tratnyek P G, Grundl T J, Haderlein S B, eds. Aquatic Redox Chemistry. Washington, DC: American Chemical Society, 315-343

Gorski C A, Scherer M M (2009). Influence of magnetite stoichiometry on $\mathrm{Fe}^{\mathrm{II}}$ uptake and nitrobenzene reduction. Environmental Science \& Technology, 43(10): 3675-3680

Gu B, Schmitt J, Chen Z, Liang L, Mccarthy J F (1994). Adsorption and desorption of natural organic matter on iron oxide: Mechanisms and models. Environmental Science \& Technology, 28(1): 38-46

Huang J, Dai Y, Liu C C, Zhang H (2019a). Effects of second metal oxides on surface-mediated reduction of contaminants by Fe(II) with iron oxide. ACS Earth \& Space Chemistry, 3(5): 680-687

Huang J, Wang Q, Wang Z, Zhang H J (2019b). Interactions and reductive reactivity in ternary mixtures of $\mathrm{Fe}(\mathrm{II})$, goethite, and phthalic acid based on a combined experimental and modeling approach. Langmuir, 35(25): 8220-8227
Huang J, Zhang H (2019a). Mn-based catalysts for sulfate radical-based advanced oxidation processes: A review. Environment International, 133: $105141-105163$

Huang J, Zhang H (2019b). Oxidant or catalyst for oxidation? The role of manganese oxides in the activation of peroxymonosulfate (PMS). Frontiers of Environmental Science \& Engineering, 13(5): 65-67

Huang J, Zhong S, Dai Y, Liu C C, Zhang $\mathrm{H}$ (2018). Effect of $\mathrm{MnO}_{2}$ phase structure on the oxidative reactivity toward bisphenol A degradation. Environmental Science \& Technology, 52(19): 1130911318

Jiang J, Pang S Y, Ma J (2009). Oxidation of triclosan by permanganate (Mn (VII)): Importance of ligands and in situ formed manganese oxides. Environmental Science \& Technology, 43(21): 8326-8331

Jiang J, Pang S Y, Ma J (2010). Role of ligands in permanganate oxidation of organics. Environmental Science \& Technology, 44(11): $4270-4275$

Jones A M, Collins R N, Rose J, Waite T D (2009). The effect of silica and natural organic matter on the Fe(II)-catalysed transformation and reactivity of $\mathrm{Fe}(\mathrm{III})$ minerals. Geochimica et Cosmochimica Acta, 73 (15): 4409-4422

Klausen J, Haderlein S B, Schwarzenbach R P (1997). Oxidation of substituted anilines by aqueous $\mathrm{MnO}_{2}$ : effect of Co-solutes on initial and quasi-steady-state kinetics. Environmental Science \& Technology, 31(9): 2642-2649

Klausen J, Troeber S P, Haderlein S B, Schwarzenbach R P (1995). Reduction of substituted nitrobenzenes by $\mathrm{Fe}(\mathrm{II})$ in aqueous mineral suspensions. Environmental Science \& Technology, 29(9): 23962404

Laha S, Luthy R G (1990). Oxidation of aniline and other primary aromatic amines by manganese dioxide. Environmental Science \& Technology, 24(3): 363-373

LaKind J S, Stone A T (1989). Reductive dissolution of goethite by phenolic reductants. Geochimica et Cosmochimica Acta, 53(5): 961971

Larese-Casanova P, Scherer M M (2007). Fe (II) sorption on hematite: New insights based on spectroscopic measurements. Environmental Science \& Technology, 41(2): 471-477

Latta D E, Bachman J E, Scherer M M (2012). Fe electron transfer and atom exchange in goethite: Influence of Al-substitution and anion sorption. Environmental Science \& Technology, 46(19): 1061410623

Li F, Liu C, Liang C, Li X, Zhang L (2008). The oxidative degradation of 2-mercaptobenzothiazole at the interface of $\beta-\mathrm{MnO}_{2}$ and water. Journal of Hazardous Materials, 154(1-3): 1098-1105

Li X, Chen Y, Zhang H (2019). Reduction of nitrogen-oxygen containing compounds (NOCs) by surface-associated $\mathrm{Fe}(\mathrm{II})$ and comparison with soluble Fe(II) complexes. Chemical Engineering Journal, 370: 782-791

Liger E, Charlet L, Van Cappellen P (1999). Surface catalysis of uranium (VI) reduction by iron(II). Geochimica et Cosmochimica Acta, 63 (19-20): 2939-2955

Liu C, Zachara J M, Foster N S, Strickland J (2007). Kinetics of reductive dissolution of hematite by bioreduced anthraquinone-2,6disulfonate. Environmental Science \& Technology, 41(22): 77307735

Lu Z, Gan J (2013). Oxidation of nonylphenol and octylphenol by 
manganese dioxide: Kinetics and pathways. Environmental Pollution, 180: 214-220

Lu Z, Lin K, Gan J (2011). Oxidation of bisphenol F (BPF) by manganese dioxide. Environmental Pollution, 159(10): 2546-2551

Maithreepala R, Doong R A (2004). Synergistic effect of copper ion on the reductive dechlorination of carbon tetrachloride by surface-bound Fe(II) associated with goethite. Environmental Science \& Technology, 38(1): 260-268

Manceau A, Silvester E, Bartoli C, Lanson B, Drits V A (1997). Structural mechanism of $\mathrm{Co}^{2+}$ oxidation by the phyllomanganate buserite. American Mineralogist, 82(11-12): 1150-1175

Martin S T (2005). Precipitation and dissolution of iron and manganese oxides. Environmental Catalysis: 61-81

Meng X, Letterman R D (1993). Effect of component oxide interaction on the adsorption properties of mixed oxides. Environmental Science \& Technology, 27(5): 970-975

Meng Y, Song W, Huang H, Ren Z, Chen S Y, Suib S L (2014). Structure-property relationship of bifunctional $\mathrm{MnO}_{2}$ nanostructures: highly efficient, ultra-stable electrochemical water oxidation and oxygen reduction reaction catalysts identified in alkaline media. Journal of the American Chemical Society, 136(32): 11452-11464

Morgan J J, Stumm W (1964). Colloid-chemical properties of manganese dioxide. Journal of Colloid Science, 19(4): 347-359

Nico P S, Zasoski R J (2000). Importance of Mn(III) availability on the rate of $\mathrm{Cr}(\mathrm{III})$ oxidation on $\delta-\mathrm{MnO}_{2}$. Environmental Science \& Technology, 34(16): 3363-3367

Park B, Dempsey B A (2005). Heterogeneous oxidation of Fe(II) on ferric oxide at neutral $\mathrm{pH}$ and a low partial pressure of $\mathrm{O}_{2}$. Environmental Science \& Technology, 39(17): 6494-6500

Pecher K, Haderlein S B, Schwarzenbach R P (2002). Reduction of polyhalogenated methanes by surface-bound $\mathrm{Fe}(\mathrm{II})$ in aqueous suspensions of iron oxides. Environmental Science \& Technology, 36(8): 1734-1741

Peretyazhko T, Zachara J M, Heald S M, Jeon B H, Kukkadapu R K, Liu C, Moore D, Resch C T (2008). Heterogeneous reduction of Tc(VII) by $\mathrm{Fe}(\mathrm{II})$ at the solid-water interface. Geochimica et Cosmochimica Acta, 72(6): 1521-1539

Redman A D, Macalady D L, Ahmann D (2002). Natural organic matter affects arsenic speciation and sorption onto hematite. Environmental Science \& Technology, 36(13): 2889-2896

Rügge K, Hofstetter T B, Haderlein S B, Bjerg P L, Knudsen S, Zraunig C, Mosbæk H, Christensen T H (1998). Characterization of predominant reductants in an anaerobic leachate-contaminated aquifer by nitroaromatic probe compounds. Environmental Science \& Technology, 32(1): 23-31

Simanova A A, Peña J (2015). Time-resolved investigation of cobalt oxidation by $\mathrm{Mn}(\mathrm{III})$-rich $\delta-\mathrm{MnO}_{2}$ using quick X-ray absorption spectroscopy. Environmental Science \& Technology, 49(18): 1086710876

Stone A T (1987). Reductive dissolution of manganese (III/IV) oxides by substituted phenols. Environmental Science \& Technology, 21(10): 979-988

Strehlau J H, Schultz J D, Vindedahl A M, Arnold W A, Penn R L (2017). Effect of nonreactive kaolinite on 4-chloronitrobenzene reduction by $\mathrm{Fe}(\mathrm{II})$ in goethite-kaolinite heterogeneous suspensions. Environmental Science. Nano, 4(2): 325-334
Sun K, Liang S, Kang F, Gao Y, Huang Q (2016). Transformation of $17 \beta$-estradiol in humic acid solution by $\varepsilon-\mathrm{MnO}_{2}$ nanorods as probed by high-resolution mass spectrometry combined with ${ }^{13} \mathrm{C}$ labeling. Environmental Pollution, 214: 211-218

Sunda W G (2010). Iron and the carbon pump. Science, 327(5966): 654655

Sundman A, Byrne J M, Bauer I, Menguy N, Kappler A (2017). Interactions between magnetite and humic substances: Redox reactions and dissolution processes. Geochemical Transactions, 18 (1): 6-17

Swindle A L, Cozzarelli I M, Elwood Madden A S (2015). Using chromate to investigate the impact of natural organics on the surface reactivity of nanoparticulate magnetite. Environmental Science \& Technology, 49(4): 2156-2162

Tao L, Zhu Z, Li F (2013). Fe(II)/Cu(II) interaction on $\alpha$-FeOOH, kaolin and $\mathrm{TiO}_{2}$ for interfacial reactions of 2-nitrophenol reductive transformation. Colloids and Surfaces. A, Physicochemical and Engineering Aspects, 425: 92-98

Taujale S, Baratta L R, Huang J, Zhang H (2016). Interactions in ternary mixtures of $\mathrm{MnO}_{2}, \mathrm{Al}_{2} \mathrm{O}_{3}$, and natural organic matter (NOM) and the impact on $\mathrm{MnO}_{2}$ oxidative reactivity. Environmental Science \& Technology, 50(5): 2345-2353

Taujale S, Zhang H (2012). Impact of interactions between metal oxides to oxidative reactivity of manganese dioxide. Environmental Science \& Technology, 46(5): 2764-2771

Taylor S D, Becker U, Rosso K M (2017). Electron transfer pathways facilitating U(VI) reduction by Fe(II) on Al- vs Fe-oxides. Journal of Physical Chemistry C, 121(36): 19887-19903

Tombácz E, Csanaky C, Illés E (2001). Polydisperse fractal aggregate formation in clay mineral and iron oxide suspensions, $\mathrm{pH}$ and ionic strength dependence. Colloid \& Polymer Science, 279(5): 484-492

Vikesland P J, Heathcock A M, Rebodos R L, Makus K E (2007). Particle size and aggregation effects on magnetite reactivity toward carbon tetrachloride. Environmental Science \& Technology, 41(15): 5277-5283

Vindedahl A M, Stemig M S, Arnold W A, Penn R L (2016). Character of humic substances as a predictor for goethite nanoparticle reactivity and aggregation. Environmental Science \& Technology, 50(3): $1200-1208$

Wang Q, Yang P, Zhu M (2019). Effects of metal cations on coupled birnessite structural transformation and natural organic matter adsorption and oxidation. Geochimica et Cosmochimica Acta, 250: 292-310

Wehrli B, Sulzberger B, Stumm W (1989). Redox processes catalyzed by hydrous oxide surfaces. Chemical Geology, 78(3-4): 167-179

Williams A G, Scherer M M (2004). Spectroscopic evidence for Fe(II)$\mathrm{Fe}(\mathrm{III})$ electron transfer at the iron oxide-water interface. Environmental Science \& Technology, 38(18): 4782-4790

Xu L, Xu C, Zhao M, Qiu Y, Sheng G D (2008). Oxidative removal of aqueous steroid estrogens by manganese oxides. Water Research, 42 (20): 5038-5044

Yanina S V, Rosso K M (2008). Linked reactivity at mineral-water interfaces through bulk crystal conduction. Science, 320(5873): 218222

Yao W, Millero F J (1996). Adsorption of phosphate on manganese dioxide in seawater. Environmental Science \& Technology, 30(2): 
$536-541$

Yu Q, Sasaki K, Tanaka K, Ohnuki T, Hirajima T (2012). Structural factors of biogenic birnessite produced by fungus Paraconiothyrium sp. WL-2 strain affecting sorption of $\mathrm{Co}^{2+}$. Chemical Geology, 310311: 106-113

Zhang H, Chen W R, Huang C H (2008). Kinetic modeling of oxidation of antibacterial agents by manganese oxide. Environmental Science \& Technology, 42(15): 5548-5554

Zhang H, Huang C H (2003). Oxidative transformation of triclosan and chlorophene by manganese oxides. Environmental Science \& Technology, 37(11): 2421-2430

Zhang H, Huang C H (2005). Reactivity and transformation of antibacterial $\mathrm{N}$-oxides in the presence of manganese oxide. Environmental Science \& Technology, 39(2): 593-601

Zhang H, Huang C H (2007). Adsorption and oxidation of fluoroquinolone antibacterial agents and structurally related amines with goethite. Chemosphere, 66(8): 1502-1512

Zhang H, Rasamani K D, Zhong S, Taujale S, Baratta L R, Yang Z (2019). Dissolution, adsorption, and redox reaction in ternary mixtures of goethite, aluminum oxides, and hydroquinone. Journal of Physical Chemistry C, 123(7): 4371-4379

Zhang H, Taujale S, Huang J, Lee G J (2015). Effects of NOM on oxidative reactivity of manganese dioxide in binary oxide mixtures with goethite or hematite. Langmuir, 31(9): 2790-2799

Zhang H, Weber E J (2009). Elucidating the role of electron shuttles in reductive transformations in anaerobic sediments. Environmental Science \& Technology, 43(4): 1042-1048

Zhang H, Weber E J (2013). Identifying indicators of reactivity for chemical reductants in sediments. Environmental Science \& Technology, 47(13): 6959-6968

Zhang Y, Yang Y, Zhang Y, Zhang T, Ye M (2012). Heterogeneous oxidation of naproxen in the presence of $\alpha-\mathrm{MnO}_{2}$ nanostructures with different morphologies. Applied Catalysis B: Environmental, 127: 182-189

Zhu M, Paul K W, Kubicki J D, Sparks D L (2009). Quantum chemical study of arsenic (III, V) adsorption on Mn-oxides: Implications for arsenic(III) oxidation. Environmental Science \& Technology, 43(17): 6655-6661

Zhu M X, Wang Z, Xu S H, Li T (2010). Decolorization of methylene blue by $\delta-\mathrm{MnO}_{2}$-coated montmorillonite complexes: Emphasizing redox reactivity of Mn-oxide coatings. Journal of Hazardous Materials, 181(1-3): 57-64

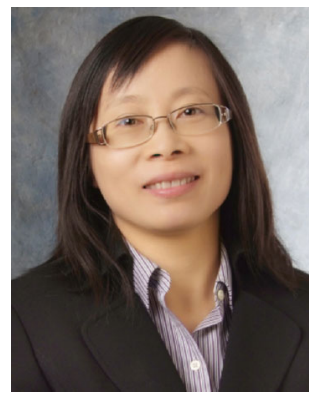

Huichun Zhang is a professor in the Department of Civil and Environmental Engineering at Case Western Reserve University. She earned her Ph.D. from Georgia Institute of Technology and B.S. and M.S. from Nanjing University. Her research focuses on the fate and transformation of contaminants in natural and engineered environments and water/wastewater treatment.

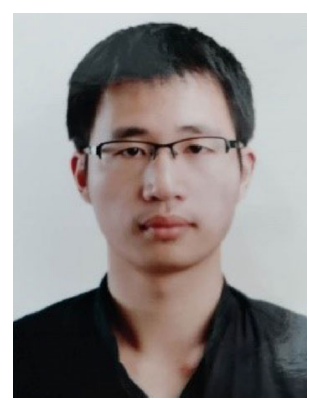

Dr. Jianzhi Huang is a postdoc at the University of Washington studying the properties of interfacial water at hydrophilic surface. He received Ph.D. in 2019 from Case Western Reserve University under the guidance of Prof. Huichun (Judy) Zhang. His research interests focus on environmental interfacial chemistry and its applications. 